\title{
Polymorphism of the PPARD Gene and Dynamic Balance Performance in Han Chinese Children
}

\author{
Yixuan Cao', Qiyue Zhang ${ }^{1}$, Jianhua Chen ${ }^{1,2}$, Zhiqiang Li ${ }^{3}$, Zhaowei Zhou', Jiawei Shen ${ }^{1}$, Dong Wang ${ }^{1}$, Dun Pan', \\ Zhuo Wang ${ }^{1}$, Dandan Ke ${ }^{4}$, Xiaofei Wang ${ }^{4}$, Dajiang Lu ${ }^{4}$, Ying Zhao ${ }^{5}$, Shulin Cheng ${ }^{5}$ and Yongyong Shi ${ }^{1,6^{*}}$
}

\begin{abstract}
Background: Athletic performances are complex traits with heritability of $\sim 66 \%$. Dynamic balance is one of the most important athletic performances, and there has been little studies for it in sports genomics. The candidate PPARD gene was reported to be able to affect muscle development for balance predisposition and influence the athletic performance including skiing triumph in the Caucasian population. This study aims to investigate whether the PPARD gene is a susceptibility gene for dynamic balance performance in Han Chinese children.

Results: A total 2244 children were recruited and their balance beam performances were measured. Five polymorphisms in the PPARD gene were genotyped through the MassARRAY Sequenom platform. Rs2016520 exerted significant association with dynamic balance performance (minor allele $C, P=0.015, P_{\text {corrected }}<0.05$ ) and was affirmed in a metaanalysis by combining previously reported Caucasian cohorts $\left(\mathrm{OR}=1.57,95 \% \mathrm{Cl}=[1.30,1.91], \mathrm{P}<10^{-5}\right)$. Another polymorphism, rs2267668, was also significantly associated with dynamic balance performance (minor allele $G, P=0.015$, $\left.P_{\text {corrected }}<0.05\right)$. In the dichotomous study, 321 cases (61\% boys and 39\% girls) and 370 controls (49\% boys and 51\% girls) in our samples were selected as representatives, and the thresholds were the mean velocity $(0.737 \mathrm{~m} / \mathrm{s}) \pm$ standard deviation $(0.264 \mathrm{~m} / \mathrm{s})$, in which rs2016520-C and rs2267668-G still remained significant $(\mathrm{Cl}=1.41$ [1.11 1.79], $\mathrm{P}=0.004$, $\mathrm{P}_{\text {corrected }}<0.016 ; \mathrm{Cl}=1.45$ [1.14 1.86], $\mathrm{P}=0.002$, $\mathrm{P}_{\text {corrected }}<0.016$ ). In different genders, consistent $\mathrm{OR}$ direction was observed for each variant.
\end{abstract}

Conclusions: Our results suggested that the PPARD gene is associated with dynamic balance performance of human being, and further studies to reveal its etiology is strongly suggested.

Keywords: Dynamic balance performance, PPARD, PPAR $\delta$, Polymorphisms

\section{Background}

The heritability of athletic performance is approximately $66 \%$, fluctuating in different sport types [1]. Generally, sports phenotypes are currently divided into explosive power, endurance, strength, flexibility, balance and neuromuscular coordination. Up to now, overall 120 SNPs were found to be associated with athletes' athletic performance. Among these SNPs, 77 were classified to

\footnotetext{
* Correspondence: shiyongyong@gmail.com

'Key Laboratory for the Genetics of Developmental and Neuropsychiatric

Disorders (Ministry of Education), Bio-X Institutes, Shanghai Jiao Tong University, Shanghai 200030, China

${ }^{6}$ Shanghai Key Laboratory of Sleep Disordered Breathing, Shanghai Jiao Tong University Affiliated Sixth People's Hospital, Shanghai 200233, China Full list of author information is available at the end of the article
}

endurance propensity and 43 to explosive/power propensity [2]. Genetic basis of balance still remains unclear in sports genomics. Sports genomics usually focuses on athletes through case-control studies, and aims to explain the structure and function of genomic regions which might result to better athletic performances [3, 4]. Recently, attention to athletic performance has gradually expanded to lower age groups [5-8]. Notably, basic athletic skills have been developed in early childhood and mature at about 5 to 8 years old [9], therefore, the studies on young children's motor phenotype make sense. Till now, there are far less studies on children than on adults regarding sports genomics. The ACTN3 gene was found to be associated with children's explosive power in

(c) The Author(s). 2019 Open Access This article is distributed under the terms of the Creative Commons Attribution 4.0 International License (http://creativecommons.org/licenses/by/4.0/), which permits unrestricted use, distribution, and 
Han Chinese [10]. NOS3 and PPARGC1A were associated with cardiorespiratory endurance in children with cystic fibrosis [11]. For children, the studied genes are also limited in explaining either explosive/power or endurance propensity, which is the same situation as that in the adults. It is essential to study the genetic basis of other athletic performance which is also of significant importance but remains unclear.

Dynamic balance is the process of maintaining or restoring a stable position while performing a task, and it is vitally important for most human locomotion [12]. The improvement of dynamic balance can enhance a series of athletic performance including vertical jump [13], shuttle-run [14] and downhill skiing [15]. Dynamic balance relies on rapid continuous feedback of vision, vestibular and somatosensory structures to perform coordinated neuromuscular movements [16]. Dynamic balance is one of the physical fitness components that could be health-related or performance-related [17]. In this article, we focused on performance-related components with all the children recruited in healthy status. Sports genomics is promising in explaining individual difference for children's dynamic balance performance.

The transcription factor peroxisome proliferator-activated receptor delta $(P P A R D)$ gene, which encodes a nuclear hormone receptor PPAR $\delta$, is among the hottest studied gene in sports genomics. PPAR $\delta$ is considered to exert important functions in the process of transcriptional repression and nuclear receptor signaling [18]. It is actively expressed in adipose tissue and skeletal muscles, mainly in type 1 (slow twitch) muscle fibers [19]. Mice studies suggested that PPAR $\delta$ plays an important role in myelination of the corpus callosum, cell differentiation, epidermal cell proliferation, and lipid metabolism [20-22]. Functional studies suggested that the PPARD gene was involved in muscle development and adaptive response to fitness training [23-26]. In mice skeletal muscle, targeted expression of activated PPAR $\delta$ triggered adaptation from type 2 muscle fibers to type 1 muscle fibers [27]. Type 1 muscle fiber has a beneficial effect on posture and endurance related performance, while type 2 muscle fiber favors strength and power related performance [28]. Large cohort studies have shown that the PPARD gene is associated with overall athletic performance in the Polish populations [28] and athletes' skiing triumph in the Russian populations [29], in which dynamic balance plays a crucial role.. Latest research on the involvement of PPAR $\delta$ with circadian rhythm inhibitors showed the enhancement of exercise performance in mice via biallelic knock out of PPAR $\delta$ repressors i.e. $C R Y 1$-/- and CRY2 -/- [30]. However, the biological mechanism of PPARD gene is not so clear.

In this study, we hypothesized that the PPARD gene might contribute to the individual variance of dynamic balance performance and tried to figure out how it could influence dynamic balance performance. In total, 2244 children were recruited, and their balance beam performances were measured. Five single nucleotide polymorphisms (SNPs) of PPARD gene including rs11571504, rs2016520, rs2267668, rs2299869 and rs3798343 were genotyped. Concisely, we conducted a quantitative trait loci (QTL) analysis, a case-control study, and a meta-analysis with one previously published data in the Caucasian population (152 cases and 610 controls) [29] to assess the association between PPARD SNPs and dynamic balance performance in Han Chinese children.

\section{Results}

Physical characteristics of all recruited children were summarized in Additional file 1: Table S1. The mean age of the children was 5.36 years old and the average BMI was $16.1 \mathrm{~kg} / \mathrm{m}^{2}$. The mean velocity walking through the 3 -meter long balance beam was $0.737 \pm 0.264 \mathrm{~m} / \mathrm{s}$. In addition, since a previous study observed correlations between measures of dynamic balance and lower-extremity maximal strength in healthy individuals across the lifespan, in which vertical jump height was one of the measurements to represent maximal strength [31], we also measured vertical jump height of each children for the further analysis. The mean vertical jump height was 17.46 $\pm 5.46 \mathrm{~cm}$. The balance beam performance and vertical jump height of the children approximately obeyed normal distributions (Additional file 1: Figure S1).

All five SNPs were in Hardy-Weinberg equilibrium (HW_P > 0.05 in Table 1). Fig. 1 illustrated the linkage disequilibrium between rs2267668 and rs2016520. Table 1 shows the quantitative trait loci results of five SNPs in the balance beam performance. Two SNPs (rs2267668 and rs2016520) were significantly associated with dynamic balance performance after multiple testing correction. The SNP rs2016520 showed significance in association with dynamic balance performance (minor allele $\mathrm{C}, \mathrm{BETA}=0.021 \mathrm{~m} / \mathrm{s}, \mathrm{P}=0.015, \mathrm{P}_{\mathrm{FDR}}=0.038$ ), and the significance remained after taking gender, weight, BMI and age as covariates to eliminate their effects respectively (minor allele $\mathrm{C}, \mathrm{BETA}=0.021 \mathrm{~m} / \mathrm{s}$, $\mathrm{P}_{\text {gender }}=0.02, \quad \mathrm{P}_{\text {gender_FDR }}=0.05, \quad \mathrm{P}_{\text {weight }}=0.013$, $\mathrm{P}_{\text {weight_FDR }}=0.032, \mathrm{P}_{\mathrm{BMI}}=0.014, \mathrm{P}_{\text {BMI-FDR }}=0.035$; BETA $\left.=0.016 \mathrm{~m} / \mathrm{s}, \quad P_{\text {age }}=0.049\right)$. Another SNP, rs2267668, was also significantly associated with dynamic balance performance $($ minor allele G, BETA = $0.023 \mathrm{~m} / \mathrm{s}, \mathrm{P}=0.015, \mathrm{P}_{\mathrm{FDR}}=0.038$ ), and $\mathrm{P}$-values maintained significant after correction by gender, weight, $\mathrm{BMI}$ and age (minor allele $\mathrm{G}, \mathrm{BETA}=0.023 \mathrm{~m} / \mathrm{s}, \mathrm{P}_{\text {gender }}=$ $0.015, \mathrm{P}_{\text {gender_FDR }}=0.05, \mathrm{P}_{\text {weight }}=0.008, \mathrm{P}_{\text {weight_FDR }}=$ $0.032 ; \mathrm{BETA}=0.022 \mathrm{~m} / \mathrm{s}, \mathrm{P}_{\mathrm{BMI}}=0.013, \mathrm{P}_{\mathrm{BMI}-\mathrm{FDR}}=0.035$; $\left.\mathrm{BETA}=0.019 \mathrm{~m} / \mathrm{s}, \mathrm{P}_{\mathrm{age}}=0.024\right)$. The $\beta$ value in the regression model pointed out the direction of the affecting way. The effect allele rs2016520-C could be a favorable allele favorable for balance beam performance. In a similar 
Table 1 Regression analyzes of five SNPs in the PPARD gene for the balance beam performance

\begin{tabular}{|c|c|c|c|c|c|c|c|c|c|c|c|c|c|c|c|c|c|c|}
\hline SNP & A1 & HW_P & Call rate & BETA & P & FDR & BETA $^{\prime}$ & $P^{1}$ & $\mathrm{DR}^{1}$ & $\mathrm{TA}^{2}$ & $p^{2}$ & $\mathrm{DR}^{2}$ & $\mathrm{ETA}^{3}$ & $P^{3}$ & $\mathrm{DR}^{3}$ & $1 A$ & 4 & $R^{4}$ \\
\hline 504 & A & 981 & 0.951 & 24 & 29 & 63 & בכטג & 38 & 423 & בכבט & 19 & 362 & 24 & 34 & 355 & 016 & 435 & .444 \\
\hline 2016520 & C & 0.998 & 0.955 & 0.021 & 0.015 & 038 & 021 & 02 & 0.05 & 0.021 & 13 & 032 & 21 & 014 & 0.035 & 016 & 049 & 0.124 \\
\hline 68 & G & 0.698 & 0.951 & 0.023 & 0.015 & 038 & 023 & 15 & 0.05 & 0.023 & .008 & 0.032 & $0.0<2$ & 013 & 035 & 0.019 & 024 & 0.124 \\
\hline 69 & $\mathrm{~T}$ & 809 & 951 & .009 & 127 & 127 & 008 & 85 & 0.485 & 1010 & 62 & 362 & -0.009 & 421 & 1 & 10 م- & 4 & 1.444 \\
\hline 3798343 & G & 0.981 & 0.951 & -0.011 & 0.211 & 0.352 & -0.011 & 0.211 & 0.351 & -0.011 & 0.187 & 0.312 & -0.011 & 0.202 & 0.337 & -0.006 & 0.444 & 0.444 \\
\hline
\end{tabular}

A1, minor allele and the effect allele with which BETA correlates; FDR, Benjamini and Hochberg procedure for controlling the false discovery rate of hypothesis tests, also known as Bonferroni's correction; BETA ${ }^{1}, \mathrm{P}^{1}, \mathrm{FDR}^{1}$ : BETA, $\mathrm{P}, \mathrm{FDR}$ after gender as a covariate to correct; BETA ${ }^{2}, \mathrm{P}^{2}, \mathrm{FDR}{ }^{2}$ : BETA, $\mathrm{P}, \mathrm{FDR}$ after weight as a covariate to correct; $B E T A^{3}, P^{3}, F D R^{3}: B E T A, P, F D R$ after BMI as a covariate to correct; BETA $A^{4}, P^{4}, F D R^{4}$ : BETA, $P, F D R$ after age as a covariate to correct; Significance threshold was $\mathrm{P}<0.05$ and significant $\mathrm{P}$-values were in bold

way, the $\beta$ value of rs2267668-G also implied its status as a favorable allele.

To preclude interference from lower-extremity maximal strength on the results, independent influence of the PPARD polymorphism on dynamic balance and lower-extremity maximal strength was explored, as shown in Table 2 and 3. Significance remained in Table 2 between dynamic balance performance and the PPARD polymorphism after corrected by the covariate of vertical jump height $(\mathrm{P}<0.05$ after corrections). In Table 3 , no significance was observed between vertical jump performance and the PPARD polymorphism either before or after it was corrected by the covariate of dynamic balance performance $(\mathrm{P}>0.05)$. Both Table 2 and 3 supported that the PPARD polymorphism influenced dynamic balance performance rather than lower-extremity maximal strength.

We performed gender specific analysis too. Consistent OR directions were observed for each variant in boys and girls groups, which implied the similar predisposition to balance beam performance in different genders. In Table 4, boys' results showed rs2016520-C (BETA = $0.027 \mathrm{~m} / \mathrm{s}, \mathrm{P}=0.033, \mathrm{P}_{\mathrm{BMI}}=0.012, \mathrm{P}$ BMI-FDR $=0.03$; $\left.\mathrm{BETA}=0.025 \mathrm{~m} / \mathrm{s}, \mathrm{P}_{\text {weight }}=0.04, \mathrm{P}_{\text {age }}=0.03\right)$ and rs2267668-G $\left(\mathrm{BETA}=0.024 \mathrm{~m} / \mathrm{s}, \mathrm{P}_{\mathrm{BMI}}=0.013, \mathrm{P}_{\text {age }}=\right.$ 0.049 ) as favorable alleles for dynamic balance performance. In Table 5, girls' results also displayed the favor of rs2016520-C $\left(B E T A=0.015 \mathrm{~m} / \mathrm{s}, \mathrm{P}_{\text {weight }}=0.012 ; \mathrm{BETA}=\right.$ $0.013 \mathrm{~m} / \mathrm{s}, \mathrm{P}_{\mathrm{BMI}}=0.012 ; \mathrm{BETA}=0.014 \mathrm{~m} / \mathrm{s}, \mathrm{P}_{\text {age }}=$

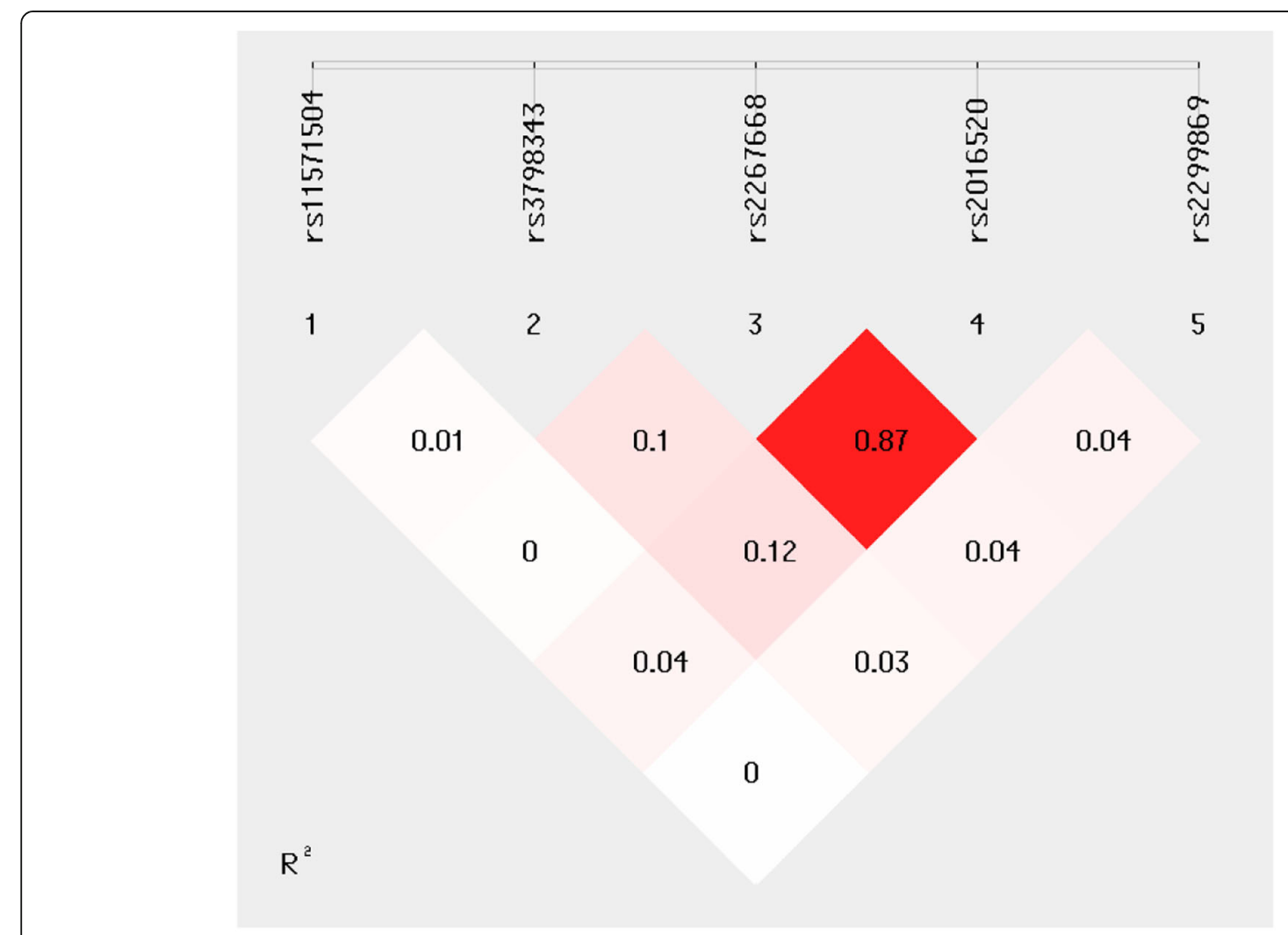

Fig. 1 Linkage disequilibrium of five SNPs in the PPARD gene 
Table 2 Vertical jump as a covariate to correct balance beam performance of the 5 SNPs in QTL testing

\begin{tabular}{cllllllll}
\hline Phenotype & SNP & A1 & BETA & $P$ & FDR & BETA $^{5}$ & $P^{5}$ & FDR $^{5}$ \\
\hline Balance beam performance & rs11571504 & A & 0.024 & 0.29 & 0.363 & 0.021 & 0.196 & 0.246 \\
& rs2016520 & C & 0.021 & 0.015 & 0.038 & 0.008 & $\mathbf{0 . 0 0 1}$ & $\mathbf{0 . 0 0 8}$ \\
& rs2267668 & G & 0.023 & 0.015 & 0.038 & 0.008 & $\mathbf{0 . 0 0 3}$ & $\mathbf{0 . 0 0 9}$ \\
& rs2299869 & T & -0.009 & 0.427 & 0.427 & 0.011 & 0.47 & 0.47 \\
& rs3798343 & G & -0.011 & 0.211 & 0.352 & 0.008 & 0.101 & 0.169 \\
\hline
\end{tabular}

$\mathrm{A} 1$, minor allele and the effect allele with which BETA correlates; $\mathrm{BETA}^{5}, \mathrm{P}^{5}, \mathrm{FDR}^{5}$ : BETA, $\mathrm{P}, \mathrm{FDR}$ after vertical jump as a covariate to correct; Significance threshold was $P<0.05$ and significant $P$-values were in bold

$0.047)$ and rs2267668-G (BETA $=0.023 \mathrm{~m} / \mathrm{s}, \mathrm{P}_{\text {weight }}=$ 0.012 ; $\left.\mathrm{BETA}=0.021 \mathrm{~m} / \mathrm{s}, \mathrm{P}_{\mathrm{BMI}}=0.012\right)$ on dynamic balance performance. In comparison with the gender-neutral dataset (Table 1), the significance of rs2016520-C and rs2267668-G slightly decreased in the gender specific dataset (Table 4 and Table 5), the major cause of which was the decline of the sample size resulting from gender split.

To further verify the association between the PPARD gene and balance beam performance, the mean velocity $(0.737 \mathrm{~m} / \mathrm{s})$ and \pm standard deviation $(0.264 \mathrm{~m} / \mathrm{s})$ were used as the thresholds to define the case and the control group. Concisely, 321 children(61\% boys and 39\% girls)were picked up as the case group for their velocity above the mean value plus standard deviation (average velocity \pm standard deviation: $1.16 \pm 0.14 \mathrm{~m} / \mathrm{s}$ ) and 370 children (49\% boys and $51 \%$ girls) were selected as the control group for their velocity below the mean value minus standard deviation (average velocity \pm standard deviation: $0.37 \pm 0.08 \mathrm{~m} / \mathrm{s}$ ). Table 6 and Table 7 demonstrates the case-control analysis results. In 321 cases and 370 controls, the two SNPs (rs2016520, rs2267668) remained significantly associated with the phenotype of balance beam performance after multiple corrections, i.e. the genetic predisposition of rs2016520-C $(\mathrm{CI}=1.41$ [1.11 1.79], $\mathrm{P}=$ $0.004, \mathrm{P}_{\mathrm{FDR}}=0.012$ in Table $6, \mathrm{P}_{\text {covariate corrections }}<0.05$ in Table 7) and rs2267668-G (CI =1.45 [1.14 1.86], $\mathrm{P}=$ $0.002, \mathrm{P}_{\text {FDR }}=0.012$ in Table 6, $\mathrm{P}_{\text {covariate corrections }}<0.05$ in Table 7) was consistent with the effect in the previous QTL analysis.

Additionally, we performed meta-analysis by integrating our case- control data with similar data from one previously reported study. A genomic study on the association of the PPARD polymorphism and skiing triumph among the Russian population was selected in our meta-analysis. Skiing is considered to be a sort of sport largely depended on dynamic balance [32-34]. In real skiing situation, there are movements like turning, vacating and diverting in the air, which requires dynamic balance to restore a stable position while performing the skiing task, therefore, dynamic balance is one of the main factors that restricts skiing triumph [34]. This Russian study recruited 152 athletes with competitive standards in skiing (including alpine skiing, ski jumping, cross-country skiing 5-10 km and 15-50 km) as cases and 610 non-athletes as controls, and then conducted genotyping to do association study [29]. Similar research method as ours were seen in their study, therefore we selected this study to carry out the meta-analysis. With the inaccessibility of detailed individual information in the Russian study, it was unable to conduct covariate corrections. The two populations were not significantly heterogeneous (heterogeneity $\mathrm{P}$-value $=0.1, \mathrm{I}^{2}=63 \%$ in Fig. 2), so that the fixed-effect model was used to estimate the overall effect of rs2016520-C on dynamic balance performance [35]. Although no significant heterogeneity was seen in the two populations, the influence of differences in age, weight, training status and other factors on the analyses and results was not completely excluded. Fig. 2 shows that the favor of dynamic balance was linked to rs2016520-C allele based on the fixed-effect $\operatorname{model}\left(\mathrm{OR}=1.57,95 \% \mathrm{CI}=[1.30,1.91], \mathrm{P}<10^{-5}\right)$. In different races, the P-values remained significant and the OR values were in the same direction. Chinese children and

Table 3 Balance beam performance as a covariate to correct vertical jump of the 5 SNPs in QTL testing

\begin{tabular}{lllllllll}
\hline Phenotype & SNP & A1 & BETA & $P$ & FDR & BETA $^{6}$ & $P^{6}$ & FDR $^{6}$ \\
\hline Vertical jump height & rs11571504 & A & -0.09 & 0.846 & 0.846 & -0.284 & 0.513 & 0.855 \\
& rs2016520 & C & 0.087 & 0.63 & 0.63 & -0.119 & 0.479 & 0.855 \\
& rs2267668 & G & 0.197 & 0.301 & 0.301 & -0.017 & 0.923 & 0.923 \\
& rs2299869 & T & -0.347 & 0.152 & 0.152 & -0.237 & 0.294 & 0.855 \\
& rs3798343 & G & -0.144 & 0.417 & 0.417 & -0.03 & 0.851 & 0.923 \\
\hline
\end{tabular}

$\mathrm{A} 1$, minor allele and the effect allele with which BETA correlates; BETA ${ }^{6}, \mathrm{P}^{6}, \mathrm{FDR}^{6}$ : BETA, $\mathrm{P}, \mathrm{FDR}$ after balance beam performance as a covariate to correct; Significance threshold was $P<0.05$ and significant $P$-values were in bold 
Table 4 Regression analyzes of five SNPs in the PPARD gene for the balance beam performance in 1155 boys

\begin{tabular}{llllllllllllllll}
\hline SNP & A1 & HW_P & NMISS & BETA & P & FDR & BETA $^{2}$ & $P^{2}$ & FDR $^{2}$ & BETA $^{3}$ & $P^{3}$ & FDR $^{3}$ & BETA $^{4}$ & $P^{4}$ & FDR $^{4}$ \\
\hline rs11571504 & A & 0.966 & 1109 & 0.046 & 0.150 & 0.251 & 0.043 & 0.164 & 0.273 & 0.046 & 0.031 & 0.144 & 0.031 & 0.285 & 0.4 \\
rs3798343 & G & 0.595 & 1109 & -0.014 & 0.274 & 0.342 & -0.012 & 0.327 & 0.409 & -0.014 & 0.012 & 0.259 & -0.009 & 0.406 & 0.406 \\
rs2267668 & G & 0.971 & 1108 & 0.024 & 0.076 & 0.191 & 0.023 & 0.072 & 0.18 & 0.024 & $\mathbf{0 . 0 1 3}$ & 0.073 & 0.024 & $\mathbf{0 . 0 4 9}$ & 0.123 \\
rs2016520 & C & 0.974 & 1115 & 0.027 & $\mathbf{0 . 0 3 3}$ & 0.163 & 0.025 & $\mathbf{0 . 0 4}$ & 0.18 & 0.027 & $\mathbf{0 . 0 1 2}$ & $\mathbf{0 . 0 3}$ & 0.025 & $\mathbf{0 . 0 3}$ & 0.123 \\
rs2299869 & T & 0.934 & 1108 & -0.011 & 0.5314 & 0.531 & -0.013 & 0.427 & 0.427 & -0.011 & 0.017 & 0.53 & -0.016 & 0.32 & 0.4 \\
\hline
\end{tabular}

$\mathrm{A} 1$, minor allele and the effect allele with which BETA correlates; FDR, Benjamini and Hochberg procedure for controlling the false discovery rate of hypothesis tests, also known as Bonferroni's correction; BETA ${ }^{2}, \mathrm{P}^{2}$, FDR $^{2}$ : BETA, P, FDR after weight as a covariate to correct; BETA ${ }^{3}, \mathrm{P}^{3}$, FDR $^{3}$ : BETA, $\mathrm{P}, \mathrm{FDR}$ after BMI as a covariate to correct; $\mathrm{BETA}^{4}, \mathrm{P}^{4}, \mathrm{FDR}^{4}$ : BETA, P, FDR after age as a covariate to correct; Significance threshold was $\mathrm{P}<0.05$ and significant $\mathrm{p}$-values were in bold

European athletes share consistent genetic predisposition on dynamic balance related performance. People owning rs2016520-C tends to have better dynamic balance related performance.

\section{Discussion}

Our findings suggested that common SNPs in the PPARD gene could play an important role in Children's dynamic balance performance. In general, the rs2016520-C allele could promote dynamic balance performance concluded from QTL analysis (BETA $>0, \mathrm{P}<0.05$ after correction as shown in Table 1$)$, case-control study $(\mathrm{CI}>1, \mathrm{P}<0.05$ after correction as shown in Table 6 and 7) and meta-analysis confirmation with the Caucasian population $\left(\mathrm{OR}=1.57,95 \% \mathrm{CI}=[1.30,1.91], \mathrm{P}<10^{-5}\right.$ in Fig. 2). Consistent BETA directions were observed for each variant in different genders, implying the similar predisposition to balance beam performance. In both genders, rs2016520-C favors better dynamic balance performance than rs2016520-T (BETA > 0 in Table 4 and 5).Although significant age difference were observed in other studies [31], significance remained in this study after taking age as a covariate $(\mathrm{P}<0.05$ in Table $1,4,5$ and 7$)$, which might be due to the elementary mature of basic motor skills in 5-8 years old children [9]. The previously reported associations between measures of dynamic balance and lower-extremity maximal strength [31] did not interfere the effect of the PPARD polymorphism on the dynamic balance performance in our study $(\mathrm{P}<0.05$ after correction in Table 2; P > 0.05 in Table 3). Studies showed that the function of neurophysiological mechanisms during dynamic balance control and maximal strength production is task-specific, although the activation of corticospinal pathways are similar [36, 37]. Furthermore, studies of spinal and corticospinal excitability showed different activation patterns in task-specific performance. For example, during the execution of strength-related isometric ankle dorsiflexion and plantarflexion, short-latency facilitation induced by transcranial magnetic stimulation was observed [38], yet it was not seen during the performance of a balance-related perturbed stance task [39].

Rs2016520, located in the 5' untranslated region of exon 4 , is the best clinically studied polymorphism in the PPARD gene. The $39 \%$ higher transcriptional activity of the PPARD promotor was observed within the mutant rs2016520-C owners than the common $\mathrm{T}$ allele ones [40]. Given that the rs2016520-T mutate into the rare C allele, the bilateral nucleotides become consensus sequence for Sp-1 binding, which might increase the affinity of Sp-1 transcriptional factor and explain the up-regulation of PPARD expression for rs2016520-C owners [40]. Moreover, studies showed that activation of PPAR $\delta$ triggered adaptation in the skeletal muscle from type 2 muscle fibers (strength and power related) to type 1 muscle fibers (postural and endurance related), enabling the mutant mice to run a longer distance in comparison with the wildtype [23, 27]. Large cohort studies in human also showed consistency in the PPARD gene regarding association with elite athlete's performances in the European populations [28, 29]. In particular, the rs2016520-C allele was associated with the triumph of skiing in the Russian population [29], in which dynamic balance could play a rather crucial role. In this study, we replicated a significant association of rs2016520-C with

Table 5 Regression analyzes of five SNPs in the PPARD gene for the balance beam performance in 1089 girls

\begin{tabular}{llllllllllllllll}
\hline SNP & A1 & HW_P & NMISS & BETA & $P$ & FDR & BETA $^{2}$ & $P^{2}$ & FDR $^{2}$ & BETA $^{3}$ & $P^{3}$ & FDR $^{3}$ & BETA $^{4}$ & $P^{4}$ & FDR $^{4}$ \\
\hline rs11571504 & A & 0.999 & 1026 & -0.01 & 0.762 & 0.762 & -0.01 & 0.032 & 0.743 & -0.01 & 0.032 & 0.747 & -0.009 & 0.657 & 0.742 \\
rs3798343 & G & 0.708 & 1026 & -0.008 & 0.524 & 0.762 & -0.01 & 0.011 & 0.381 & -0.007 & 0.011 & 0.525 & -0.002 & 0.745 & 0.846 \\
rs2267668 & G & 0.604 & 1026 & 0.021 & 0.096 & 0.478 & 0.023 & $\mathbf{0 . 0 1 2}$ & 0.056 & 0.021 & $\mathbf{0 . 0 1 2}$ & 0.088 & 0.013 & 0.056 & 0.343 \\
rs2016520 & C & 0.951 & 1028 & 0.013 & 0.287 & 0.718 & 0.015 & $\mathbf{0 . 0 1 2}$ & 0.204 & 0.013 & $\mathbf{0 . 0 1 2}$ & 0.28 & 0.014 & $\mathbf{0 . 0 4 7}$ & 0.21 \\
rs2299869 & $\mathrm{T}$ & 0.884 & 1025.000 & -0.006 & 0.726 & 0.762 & -0.005 & 0.015 & 0.722 & -0.005 & 0.015 & 0.718 & -0.003 & 0.746 & 0.846 \\
\hline
\end{tabular}

A1, minor allele and the effect allele with which BETA correlates; FDR, Benjamini and Hochberg procedure for controlling the false discovery rate of hypothesis tests, also known as Bonferroni's correction; BETA ${ }^{2}, \mathrm{P}^{2}$, FDR ${ }^{2}$ : BETA, $\mathrm{P}$, FDR after weight as a covariate to correct; BETA ${ }^{3}, \mathrm{P}^{3}$, FDR ${ }^{3}$ : BETA, $\mathrm{P}, \mathrm{FDR}^{\mathrm{B}}$ after BMI as a covariate to correct; $\mathrm{BETA}^{4}, \mathrm{P}^{4}, \mathrm{FDR}^{4}$ : BETA, $\mathrm{P}, \mathrm{FDR}$ after age as a covariate to correct; Significance threshold was $\mathrm{P}<0.05$ and significant $\mathrm{p}$-values were in bold 
Table 6 Case-control study on balance beam performance

\begin{tabular}{|c|c|c|c|c|c|c|c|c|c|c|c|}
\hline SNP & Call rate & OR 95\% Cl & Genotype fi & quency & & $P$ & FDR & Allele frequ & cy & $P$ & FDR \\
\hline rs11571504 & 0.982 & $1.33[0.7 \sim 2.55]$ & AA & AT & $\pi$ & 0.265 & 0.389 & A & $\mathrm{T}$ & 0.379 & 0.379 \\
\hline Case & & & $0(0.000)$ & $20(0.063)$ & 298(0.937) & & & $20(0.031)$ & 616(0.969) & & \\
\hline Control & & & $1(0.003)$ & $16(0.042)$ & $362(0.955)$ & & & $18(0.024)$ & $740(0.976)$ & & \\
\hline rs3798343 & 0.982 & $0.85[0.68 \sim 1.07]$ & $\mathrm{CC}$ & $C G$ & GG & 0.212 & 0.347 & C & G & 0.159 & 0.265 \\
\hline Case & & & 158(0.497) & $135(0.425)$ & $25(0.079)$ & & & $451(0.709)$ & 185(0.291) & & \\
\hline Control & & & $177(0.467)$ & $157(0.414)$ & $45(0.119)$ & & & $511(0.674)$ & $247(0.326)$ & & \\
\hline rs2267668 & 0.982 & $1.45[1.14 \sim 1.86]$ & $\mathrm{AA}$ & $A G$ & GG & 0.005 & 0.013 & A & G & 0.002 & 0.012 \\
\hline Case & & & $161(0.506)$ & $133(0.418)$ & $24(0.075)$ & & & 455(0.715) & $181(0.285)$ & & \\
\hline Control & & & 238(0.628) & $119(0.314)$ & $22(0.058)$ & & & 595(0.785) & 163(0.215) & & \\
\hline rs2016520 & 0.973 & 1.41 [1.11 1.79] & $\mathrm{CC}$ & $\mathrm{CT}$ & $\pi$ & 0.004 & 0.013 & C & T & 0.004 & 0.012 \\
\hline Case & & & $26(0.081)$ & $143(0.445)$ & $152(0.474)$ & & & 195(0.304) & 447(0.696) & & \\
\hline Control & & & $26(0.070)$ & $123(0.332)$ & $221(0.597)$ & & & $175(0.236)$ & $565(0.764)$ & & \\
\hline rs2299869 & 0.982 & 0.86 [0.62 1.19] & $\mathrm{CC}$ & $\mathrm{CT}$ & $\Pi$ & 0.541 & 0.509 & C & $\mathrm{T}$ & 0.35 & 0.379 \\
\hline Case & & & 251(0.789) & 63(0.198) & $4(0.013)$ & & & $565(0.888)$ & $71(0.112)$ & & \\
\hline Control & & & $291(0.768)$ & $79(0.208)$ & $9(0.024)$ & & & $661(0.872)$ & $97(0.128)$ & & \\
\hline
\end{tabular}

FDR, Benjamini and Hochberg procedure for controlling the false discovery rate of hypothesis tests, also known as Bonferroni's correction; Significance threshold was $\mathrm{P}<0.05$ and significant $\mathrm{p}$-values were in bold

dynamic balance performance in the Han Chinese children. After multiple corrections and further confirmation among the different populations, our results suggest the rs2016520-C as a favorable allele for dynamic balance performance.

rs2267668-G was significantly associated with dynamic balance performance concluded from QTL analysis (BETA $>0, \mathrm{P}<0.05$ after correction in Table 1) and case-control analysis $(\mathrm{CI}>1, \mathrm{P}<0.05$ after correction in Table 6 and 7). In the boys' or girls' dataset, BETA directions were observed consistent with gender-neutral ones ( BETA > 0 for rs2267668-G, shown in Table 1, 4 and 5), although the significance decreased due to the split of the sample size. In both genders, rs2267668-G favors better dynamic balance performance. Previous studies showed that PPARD rs2267668 A/G SNP had impacts on the improvement of mitochondrial function and aerobic physical fitness $[41,42]$. A blunted increase in individual anaerobic threshold (i.e. worse aerobic physical fitness) was observed in rs2267668-G, which suggested the less effectiveness of aerobic exercise training, while rs2267668-G of cultured human myotubes displayed low skeletal muscle mitochondrial function [41]. In a physical and dietary lifestyle intervention, the minor $\mathrm{G}$ allele of rs2267668 was associated with less reduction in nonvisceral adipose tissue mass as well as blunted increase in relative muscle volume of the leg [42]. The G allele of rs2267668 showed better dynamic balance performance in Chinese children in our study. The influence effect of the rs2267668 site still needs further investigation from experiments. The marginal positive result of the correlation between rs 2267668 and dynamic balance performance might be caused by the linkage disequilibrium with the 5'UTR functional rs2016520.

\section{Conclusion}

In summary, we found the significant association of one 5'UTR variant (rs2016520-C) and one intron variant (rs2267668-G) in the PPARD gene with the balance beam performance. Our results suggest that the PPARD

Table 7 Gender, weight, BMI and age as covariates in case-control study of balance beam performance

\begin{tabular}{|c|c|c|c|c|c|c|c|c|c|c|c|c|c|c|}
\hline NP & $\mathrm{A} 1$ & HW_P & $1^{1}$ & $P^{1}$ & $\mathrm{R}^{1}$ & $1^{2}$ & $P^{2}$ & $\mathrm{FDR}^{2}$ & OR 9 & $P^{3}$ & $\mathrm{FDR}^{3}$ & UR & $P^{4}$ & $\mathrm{FDR}^{4}$ \\
\hline 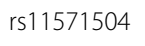 & A & 99 & 6] & 8 & 22 & ] & 99 & 09 & 5] & 23 & 423 & 5] & .736 & 36 \\
\hline 343 & G & 0.904 & 1.49] & 39 & 0.233 & $0.84[\mathrm{C}$ & 49 & 0.248 & $0.84[0$ & 0.133 & 0.221 & 0.85 & 0.268 & 0.335 \\
\hline 68 & G & 0.856 & 84] & 104 & 0.016 & 1.47 & 002 & 0.014 & 1.46 & 0.002 & 0.01 & 1.5 & I. & 0.051 \\
\hline 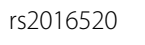 & C & 935 & 87. & 06 & 016 & 1. & 5 & 0.016 & 1 & 4 & 0.01 & 6] & 0.041 & 0.103 \\
\hline 2299869 & $\mathrm{~T}$ & 0.775 & $0.89[0.64-1.22]$ & 0.461 & 0.461 & $0.84[0.6 \sim 1.16]$ & 0.285 & 0.356 & $0.86[0.63 \sim 1.19]$ & 0.374 & 0.423 & $0.77[0.52 \sim 1.15]$ & 0.195 & 0.326 \\
\hline
\end{tabular}

$A 1$, minor allele and the effect allele with which BETA correlates; FDR, Benjamini and Hochberg procedure for controlling the false discovery rate of hypothesis tests, also known as Bonferroni's correction; BETA ${ }^{1}, \mathrm{P}^{1}, \mathrm{FDR}^{1}$ : BETA, $\mathrm{P}, \mathrm{FDR}$ after gender as a covariate to correct; $B E T A^{2}, \mathrm{P}^{2}, \mathrm{FDR}^{2}$ : $B E T A, P, F D R$ after weight as a covariate to correct; $B E T A^{3}, P^{3}, F^{3} R^{3}$ : BETA, P, FDR after BMI as a covariate to correct; BETA ${ }^{4}, \mathrm{P}^{4}, \mathrm{FDR}^{4}$ : BETA, $\mathrm{P}, \mathrm{FDR}$ after age as a covariate to correct; Significance threshold was $\mathrm{P}<0.05$ and significant $\mathrm{p}$-values were in bold 


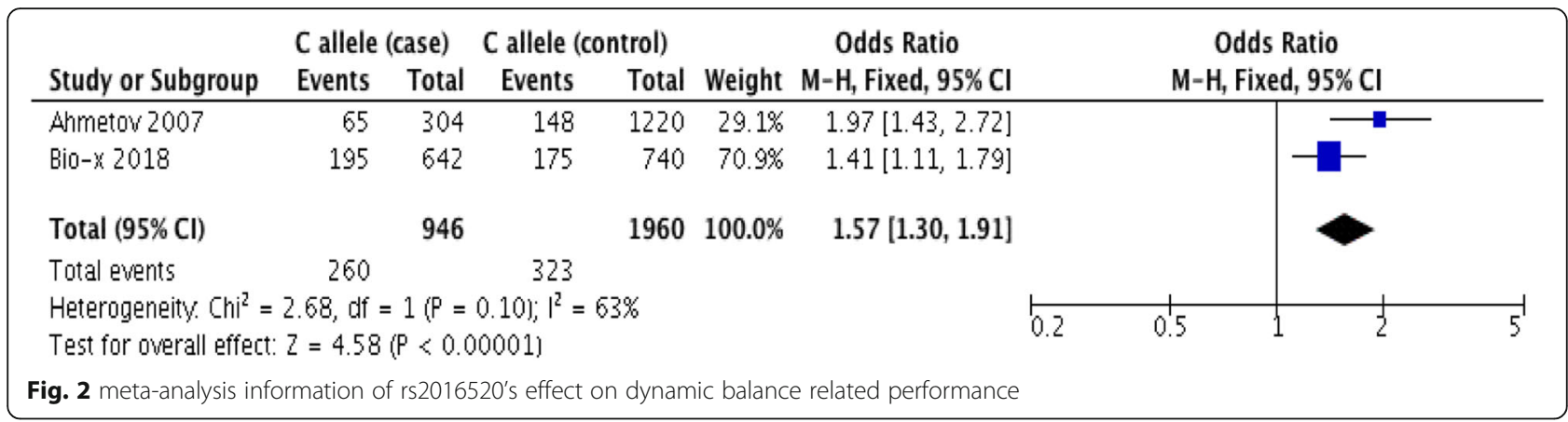

gene is associated with dynamic balance performance of children, and further studies to reveal its etiology is strongly suggested.

\section{Methods}

\section{Recruited volunteers' dataset}

With the purpose of the study clearly explained to the parents, children, and all informed consent accessible to the children's guardians, our study was scrutinized and approved by the local Ethical Committee of Human Genetics. The research was conducted in accordance with institutional requirements and the Declaration of Helsinki Principles. Overall 2244 unrelated healthy Chinese children (1155 boys and 1089 girls; average age \pm standard deviation: $5.36 \pm 1.03$ years old) were recruited. All the children were of Han Chinese origin and lived in Shanghai. Oral epithelial cells were collected through oral swabs in identified tubes for follow-up experiments.

\section{Phenotypes measurement}

All the tests of balance beam performance and vertical jump height were conducted and recorded by the Shanghai University of Sports based on the standard manual for Chinese national physique determination (child part) [43]. We made efforts to ensure the children to fully understand the process of measurements and reflect their true levels. The performance of walking through the balance beam was to evaluate children's dynamic balance performance. The balance beam was 3 meters long, 10 centimeters wide and 30 centimeters high. A 20 centimeters long, 20 centimeters wide, and 30 centimeters high board were added for step to each end of the balance beam as shown in Additional file 1: Figure S2. During the test, the children were guided to stood on the board and faced the balance beam with arms lifted horizontally. When 'start' was heard, the children proceeded as fast as possible. Walking through time was recorded and then the average velocity was calculated for further research. As for the vertical jump test, the Vertec apparatus was used. It was of steel frame construction with horizontal vanes which were rotated out of the way by the hand to indicate the height reached. We firstly recorded the standing height of each child with one arm fully extended upward, then instructed them to jump upwards vigorously and touch the highest possible vane. The vertical jump height was the difference between the maximal jump height and standing height. The score was recorded in centimeters. Each test allowed the children to perform three times to pick out the best score for the analysis. The same equipment under the same condition was used in each time to eliminate systematical errors.

\section{SNPs selection and genotyping}

The PPARD gene is located on chromosome 6p21.2p21.1 and it spans about $92.62 \mathrm{~kb}$ of DNA and contains several SNPs. We downloaded the PPARD gene information of the Southern Han Chinese population from the 1000 Genomes website and selected 5 common tag SNPs (rs3798343, rs2299869, rs2267668, rs11571504, and rs2016520) as shown in Additional file 1: Figure S3 and Additional file 1: Table S2 through the Haploview 4.2 Software (Ensembl GRCh37 2018) [44]. To be exact, the downloaded marker information and linkage pedigree format were firstly uploaded to the Haploview 4.2 Software. Then, major thresholds were set as listed below: HW-P value cutoff at 0.05 , minimal genotype percentage at 95\%, maximal Mendel errors at 1, minor allele frequency (MAF) at $0.05, \mathrm{r}^{2}$ threshold at 0.8 [45]. For the linkage format, pairwise comparisons of markers over $500 \mathrm{~kb}$ apart were set to be ignored. Afterwards, 'Pairwise tagging only' model was selected and the five tag SNPs were then given by the software. TIANamp Swab DNA Kit (TIANGEN) was used to extract genomic DNA from oral epithelial cells. The genomic DNA was obtained from participants' epithelial mouth cells using high yield oral swab genomic DNA extraction kit. $2 \mu \mathrm{l}$ DNA solution of each child was used for genotyping. All SNPs were genotyped on the Sequenom Massarray platform in Bio-x institute. SNPs were all genotyped by a call rate $\geq 95 \%$, which suggested the failure rate of genotyping below 5\%. The genotyping rate of each SNP in each studied group was listed in the relevant table. The process of Sequenom Massarray SNP genotyping 
involved polymerase chain reaction (PCR), Shrimp alkaline phosphatase (SAP) reaction, single base extension, resin cleanup and detection on mass spectrometry [46].

\section{Statistical analysis}

We used SHEsisPlus platform [47-49] to carry out statistical analysis, including Hardy-Weinberg equilibrium (HWE), linkage disequilibrium (LD), quantitative trait loci(QTL)and case-control analysis for 5 SNPs in the PPARD gene. QTL analyses were firstly carried out to find out the genotypes that might be related to the quantitative trait. The multiple-testing procedure was used to eliminate the duplicate effects of 5 SNPs to control the false discovery rate [50]. The covariate of gender, weight, BMI, age and vertical jump height were further used in the regression model to eliminate their effect on the balance beam performance based on SHEsisPlus [47-49]. After taking these factors as covariates to eliminate their effects on dynamic balance performance, the sports genomics studies could be more meaningfully interpreted. The statistical significance was set at the threshold $\mathrm{P}<0.05$. The OR value in the case-control analysis indicates the influence direction and intensity of the PPARD loci on the balance trait. CI values of the Han Chinese children are used to estimate the range of the children's overall parameters. In addition, we searched related literature to conduct meta-analysis, which was carried out on RevMan5.3 software under Cochran guidelines [33]. The Z-test was used to detect significance and the heterogeneity $\mathrm{Q}$ test was used to assess whether effects differ among different populations. In this test, the heterogeneity $\mathrm{P}>0.05$ (Fig. 2) suggests that the two populations are a homogeneous collection. Therefore, the fixed effect Mantel-Haenszel model was used.

\section{Additional file}

Additional file 1: Table S1. Physical characteristics of all recruited children. Table S2. Genetic information of five markers. Figure S1. Distribution of the balance beam and vertical jump performance in the Han Chinese children. Figure S2. Diagram of balance beam performance. Figure S3. Location of the five single nucleotide polymorphisms (SNPs) in the PPARD gene. (DOCX $365 \mathrm{~kb}$ )

\section{Abbreviations \\ CEU: Utah residents with Northern and Western Europe; CHR: Chromosome; CHS: Han Chinese in South; FDR: Benjamini and Hochberg procedure for controlling the false discovery rate of hypothesis tests; HWE: Hardy- Weinberg equilibrium; MAF: minor allele frequency; OR: Odds ratio; PPARD/ PPARS: peroxisome proliferator-activated receptors delta; SD: Standard deviation; SNP: Single nucleotide polymorphism}

\section{Acknowledgments}

All the participants are appreciated for their contribution and cooperation

\section{Funding}

This work was supported by the 973 Program (2015CB559100), the National Key R\&D Program of China (2016YFC1306903, 2017YFC0908105), the Natural Science Foundation of China $(81421061,81701321,31571012,81501154)$, the
Program of Shanghai Subject Chief Scientist (15XD1502200), the National Program for Support of Top-Notch Young Professionals, Shanghai Key Laboratory of Psychotic Disorders (13dz2260500), the National Program for Support of Top-Notch Young Professionals to Y.S., Shanghai Hospital Development Center (SHDC12016115), Shanghai Mental Health Center (2016-fx-02), Shanghai Science and Technology Committee (17JC1402900, 17490712200) and shanghai municipal health commission (ZK2015B01, 201540114)

\section{Availability of data and materials}

The original datasets used and analyzed during the current study are available from the coresponding author on reasonable request.

\section{Authors' contributions}

YYS., DP, ZW obtained financial support and YYS.SC, YZ, DL, KH supervised the study; YC, QZ and JC conceived and designed the study; SC, YZ, DL, DK, $X W$ collected phenotype information. YC and QZ performed genotyping and data analysis; ZZ, ZL and JS provided technical support. DW conducted preliminary bioinformatics transformation; $\mathrm{YC}$ interpreted the data and drafted the manuscript. All authors read and approved the final manuscript.

\section{Ethics approval and consent to participate}

With the purpose of the study clearly explained to the parents,children and all informed consent accessible to children's guardians, our study was scrutinized and approved by the local Ethical Committee of Human Genetics.

Consent for publication

Not applicable.

\section{Competing interests}

The authors declare no competing interests.

\section{Publisher's Note}

Springer Nature remains neutral with regard to jurisdictional claims in published maps and institutional affiliations.

\section{Author details}

${ }^{1}$ Key Laboratory for the Genetics of Developmental and Neuropsychiatric Disorders (Ministry of Education), Bio-X Institutes, Shanghai Jiao Tong University, Shanghai 200030, China. ${ }^{2}$ Shanghai Key Laboratory of Psychotic Disorders, Shanghai Mental Health Center, Shanghai Jiao Tong University School of Medicine, Shanghai 200030, China. ${ }^{3}$ Qingdao University, Metabolic Disease Institute, Qingdao 266003, China. ${ }^{4}$ Department of Human Sports Science, Shanghai University of Sport, Shanghai 200438, China. ${ }^{5}$ Physical Education Department, Shanghai Jiao Tong University, Shanghai 200240, China. ${ }^{6}$ Shanghai Key Laboratory of Sleep Disordered Breathing, Shanghai Jiao Tong University Affiliated Sixth People's Hospital, Shanghai 200233, China.

Received: 8 March 2019 Accepted: 15 May 2019

Published online: 23 May 2019

\section{References}

1. De Moor MHM, Spector TD, Cherkas LF, et al. Genome-wide linkage scan for athlete status in 700 British female DZ twin pairs[J]. Twin Res Hum Genet. 2007:10(6):812-20.

2. Ahmetov II, Fedotovskaya ON. Current Progress in Sports Genomics, Makowski G S, editor. Adv Clin Chem. 2015;70:247-314.

3. Pitsiladis $Y$, Wang $G$, Wolfarth $B$. Genomics of elite sporting performance: what little we know and necessary advances (vol 47, pg 550, 2013)[J]. Br J Sports Med. 2013;47(10):656.

4. Wang $\mathrm{G}$, Tanaka M, Eynon N, et al.: The Future of Genomic Research in Athletic Performance and Adaptation to Training, Posthumus M, Collins M, editor, Genetics and Sports, 2nd Revised and Extended Edition, 2016: 55-67.

5. 이영란. Comparisons of Talent Children in Sports and General Students of Elementary School on Physique, Isokinetic Strength and Anaerobic Exercise Capacity[J]. The Korean Society of Sports Science, 2014, 23(6): 1225-1234.

6. Mueller J, Boehm B, Elmenhorst J, et al. Reduction of exercise capacity in children from summer to winter is associated with lower sporting activity: a serial study[]. Pediatr Res. 2013;74(4):439-42.

7. Song J, 유성호, 정현 철, et al. Comparison of Skeletal Maturation, Bone Mineral Density, Physical Fitness, Aerobic and Anaerobic Capacity in 
Children Who Participated in Different Sports[]]. The Korean Journal of Growth and Development, 2016, 24(1): 37-44.

8. Lubans DR, Morgan PJ, Cliff DP, et al. Fundamental Movement Skills in Children and Adolescents Review of Associated Health Benefits[]]. Sports Medicine. 2010;40(12):1019-35.

9. Malina RM, Katzmarzyk PT. Physical activity and fitness in an international growth standard for preadolescent and adolescent children[J]. Food Nutr Bull. 2006;27(4):S295-313.

10. Zhang Q, Cao Y, Chen J, et al. ACTN3 is associated with children's physical fitness in Han Chinese[J]. Mol Genet Genomics. 2019;294(1):47-56.

11. Yvert T, Santiago C, Santana-Sosa E, et al. Physical-Capacity-Related Genetic Polymorphisms in Children with Cystic Fibrosis[]]. Pediatr Exerc Sci. 2015; 27(1):102-12.

12. Winter D A, Patla A E, Frank J S J M P T. Assessment of balance control in humans[J], 1990, 16(1-2): 31-51.

13. Kean CO, Behm DG, Young WB. Fixed foot balance training increases rectus femoris activation during landing and jump height in recreationally active women[J]. Journal of Sports Science and Medicine. 2006;5(1):138-48.

14. Yaggie J A, Campbell B M J J O S, Research C. Effects of balance training on selected skills[]], 2006, 20(2): 422-428.

15. Malliou P, Amoutzas $K$, Theodosiou A, et al. Proprioceptive training for learning downhill skiing[J]. Percept Mot Skills. 2004;99(1):149-54.

16. Lawrence EL, Cesar G, Bromfield MR, et al. Strength, Multijoint Coordination, and Sensorimotor Processing Are Independent Contributors to Overall Balance Ability[J]. Biomed Research International. 2015.

17. Caspersen C J, Powell K E, Christenson G M. Physical activity, exercise, and physical fitness: definitions and distinctions for health-related research[]]. Public health reports (Washington, D.C. : 1974), 1985, 100(2): 126-31.

18. Berger J, Moller DE. The mechanisms of action of PPARs[]]. Annu Rev Med. 2002;53:409-35.

19. Loviscach M, Rehman N, Carter L, et al. Distribution of peroxisome proliferator-activated receptors (PPARs) in human skeletal muscle and adipose tissue: relation to insulin action[J]. Diabetologia. 2000;43(3):304-11.

20. Lee $\mathrm{C}-\mathrm{H}$, Olson P, Hevener A, et al. PPARS regulates glucose metabolism and insulin sensitivity[J], 2006, 103(9): 3444-3449.

21. Feige JN, Gelman L, Michalik L, et al. From molecular action to physiological outputs: Peroxisome proliferator-activated receptors are nuclear receptors at the crossroads of key cellular functions[]]. Prog Lipid Res. 2006;45(2):120-59.

22. Wang $\mathrm{YX}$, Lee $\mathrm{CH}$, Tiep $\mathrm{S}$, et al. Peroxisome-proliferator-activated receptor delta activates fat metabolism to prevent obesity[]]. Cell. 2003;113(2):159-70.

23. Luquet S, Lopez-Soriano J, Holst D, et al. Peroxisome proliferator-activated receptor delta controls muscle development and oxydative capability[]]. Faseb Journal, 2003, 17(13): 2299-+.

24. Jones $\mathrm{N}$, Kiely J, Suraci B, et al. A genetic-based algorithm for personalized resistance training[J]. Biology of Sport. 2016;33(2):117-26.

25. Mahoney D J, Parise G, Melov S, et al. Analysis of global mRNA expression in human skeletal muscle during recovery from endurance exercise[J]. Faseb Journal, 2005, 19(8): 1498-+

26. Domanska-Senderowska D, Snochowska A, Szmigielska P, et al. ANALYSIS OF THE PPARD GENE EXPRESSION LEVEL CHANGES IN FOOTBALL PLAYERS IN RESPONSE TO THE TRAINING CYCLE[]]. Balkan Journal of Medical Genetics. 2018;21(3):19-25.

27. Wang $Y X$, Zhang $C L$, Yu RT, et al. Regulation of muscle fiber type and running endurance by PPAR delta[J]. Plos Biology. 2004;2(10):1532-9.

28. Maciejewska-Karlowska A, Hanson ED, Sawczuk M, et al. Genomic haplotype within the Peroxisome Proliferator-Activated Receptor Delta ( PPARD) gene is associated with elite athletic status[]]. Scand J Med Sci Sports. 2014;24(3):E148-55.

29. Akhmetov II, Astranenkova IV, Rogozkin VA. Association of PPARD gene polymorphism with human physical performance[]]. Mol Biol (Mosk). 2007; 41(5):852-7.

30. Jordan S D, Kriebs A, Vaughan M, et al. CRY1/2 Selectively Repress PPAR delta and Limit Exercise Capacity[J]. Cell Metabolism, 2017, 26(1): 243-+.

31. Muehlbauer T, Gollhofer A, Granacher U. Associations Between Measures of Balance and Lower-Extremity Muscle Strength/Power in Healthy Individuals Across the Lifespan: A Systematic Review and Meta-Analysis[]]. Sports Medicine. 2015;45(12):1671-92.

32. Hongguang YYMA, Yantao L, et al. Relationship between Lower Limb Muscle Strength and Static Balance Ability of National Elite Men's Freestyle Skiing Aerials Athletes[]]. Journal of Shenyang Sport University. 2012.
33. Moxnes JF, Sandbakk O, Hausken K. A simulation of cross-country skiing on varying terrain by using a mathematical power balance model[j]. Open access journal of sports medicine. 2013;4:127-39.

34. Zhang $Y$, Kong $L$. The function of body banlance in downhill skiing [J]. Snow and ice sports. 2001;3:28-9 (in Chinese).

35. Furlan AD, Pennick V, Bombardier C, et al. 2009 Updated Method Guidelines for Systematic Reviews in the Cochrane Back Review Group[J]. Spine. 2009; 34(18):1929-41.

36. Schubert M, Beck S, Taube W, et al. Balance training and ballistic strength training are associated with task-specific corticospinal adaptations[]]. European Journal of Neuroscience. 2008;27(8):2007-18.

37. Beck S, Taube W, Gruber M, et al. Task-specific changes in motor evoked potentials of lower limb muscles after different training interventions[]]. Brain Res. 2007;1179:51-60.

38. Morita $\mathrm{H}$, Olivier E, Baumgarten J, et al. Differential changes in corticospinal and la input to tibialis anterior and soleus motor neurones during voluntary contraction in man[J]. Acta Physiol Scand. 2000;170(1):65-76.

39. Taube W, Schubert M, Gruber M, et al. Direct corticospinal pathways contribute to neuromuscular control of perturbed stance[J]. J Appl Physiol. 2006;101(2):420-9.

40. Skogsberg J, Kannisto K, Cassel TN, et al. Evidence that peroxisome proliferator-activated receptor delta influences cholesterol metabolism in men[J]. Arteriosclerosis Thrombosis and Vascular Biology. 2003;23(4):637-43.

41. Stefan N, Thamer C, Staiger H, et al. Genetic variations in PPARD and PPARGC1A determine mitochondrial function and change in aerobic physical fitness and insulin sensitivity during lifestyle intervention[J]. J Clin Endocrinol Metab. 2007:92(5):1827-33.

42. Thamer C, Machann J, Stefan N, et al. Variations in PPARD determine the change in body composition during lifestyle intervention: A whole-body magnetic resonance study[]]. J Clin Endocrinol Metab. 2008;93(4):1497-500.

43. General Administration of Sport of China. Standard manual for Chinese national physique determination (child part) [M]. Peoples Sports Publishing House, 2003. (in Chinese)

44. Barrett JC, Fry B, Maller J, et al. Haploview: analysis and visualization of LD and haplotype maps[]]. Bioinformatics. 2005;21(2):263-5.

45. De Bakker PIW, Burtt NP, Graham RR, et al. Transferability of tag SNPs in genetic association studies in multiple populations[]]. Nat Genet. 2006:38(11):1298-303.

46. Gabriel S, Ziaugra L, Tabbaa D. SNP Genotyping Using the Sequenom MasSARRAY iPLEX Platform[J]; 2009.

47. Shi YY, He L. SHEsis, a powerful software platform for analyses of linkage disequilibrium, haplotype construction, and genetic association at polymorphism loci[J]. Cell Res. 2005;15(2):97-8.

48. Li Z, Zhang Z, He Z, et al. A partition-ligation-combination-subdivision EM algorithm for haplotype inference with multiallelic markers: update of the SHEsis (http://analysis.bio-x.cn)[]]. Cell Res. 2009;19(4):519-23.

49. Shen J, Li Z, Chen J, et al. SHEsisPlus, a toolset for genetic studies on polyploid species[]]. Sci Rep. 2016;6.

50. Benjamini Y, Hochberg Y J J O T R S S. Controlling the False Discovery Rate: A Practical and Powerful Approach to Multiple Testing[]], 1995, 57(1): 289-300.

Ready to submit your research? Choose BMC and benefit from:

- fast, convenient online submission

- thorough peer review by experienced researchers in your field

- rapid publication on acceptance

- support for research data, including large and complex data types

- gold Open Access which fosters wider collaboration and increased citations

- maximum visibility for your research: over $100 \mathrm{M}$ website views per year

At $\mathrm{BMC}$, research is always in progress.

Learn more biomedcentral.com/submissions 